\title{
CARACTERÍSTICAS FÍSICAS E QUÍMICAS DE FRUTOS DE MARACUJAZEIRO-AMARELO ENXERTADO EM TRÊS PORTA-ENXERTOS ${ }^{1}$
}

\author{
JOSÉ CARLOS CAVICHIOLI², LUIZ DE SOUZA CORRÊA ${ }^{3}$, \\ APARECIDA CONCEIÇÃO BOLIANI ${ }^{4}$, PEDRO CÉSAR DOS SANTOS ${ }^{5}$
}

RESUMO - O mercado de frutas frescas do maracujá-amarelo valoriza a qualidade interna e externa dos frutos. Assim, este trabalho teve o objetivo de avaliar o efeito do porta-enxerto e do tipo de enxertia na qualidade dos frutos de maracujazeiro-amarelo (Passiflora edulis Sims). O experimento foi conduzido no município de Adamantina-SP, no período de abril de 2006 a junho de 2007, adotando-se o delineamento em blocos ao acaso, em esquema fatorial $3 \times 2+1$ tratamento adicional, com quatro repetições. Os porta-enxertos avaliados foram: P. edulis (maracujá-amarelo), P. alata (maracujá-doce) e P. gibertii (maracujá-giberti), em dois tipos de enxertia: hipocotiledonar e convencional por garfagem tipo fenda cheia e um tratamento adicional, sem enxertia. Utilizou-se como copa o maracujazeiro-amarelo (Passiflora edulis Sims). Avaliaram-se o comprimento, o diâmetro, a massa fresca e a classificação dos frutos no período de novembro de 2006 a abril de 2007, a massa e a espessura da casca dos frutos, o rendimento do suco, o teor de sólidos solúveis totais (SST), a acidez total titulável (ATT) e o ratio (SST/ATT) dos frutos no mês de dezembro de 2006. O diâmetro e a massa fresca de frutos obtidos de plantas enxertadas sobre $P$. gibertii foram inferiores em relação aos de plantas pé-franco e aos de plantas enxertadas sobre $P$. alata. Os maiores comprimentos de frutos foram encontrados em plantas não enxertadas. Os porta-enxertos utilizados não influenciaram no teor de SST, na ATT e no ratio. O método de enxertia não interfere no diâmetro, no comprimento, na massa fresca dos frutos, na massa e na espessura da casca, no rendimento do suco e no teor de SST.

Termos para indexação: maracujá-amarelo, Passifloraceae, qualidade dos frutos.

\section{PHYSICAL AND CHEMICAL CHARACTERISTICS OF YELLOW PASSION FRUIT GRAFTED ON THREE ROOTSTOCKS}

\begin{abstract}
The fresh fruit market of yellow passion fruit values the quality of internal and external fruits. Thus, the objective of this study was to evaluate the effect of the rootstocks and type of grafting in quality of yellow passion fruit (Passiflora edulis Sims). The experiment was carried in Adamantina, SP, Brazil, from April 2006 to June 2007, adopting the experimental design in randomized blocks in a $3 \times 2$ factorial scheme and an additional treatment, with four replicates. The studied rootstocks were: P. edulis (yellow passion fruit), $P$. alata (sweet passion fruit) and $P$. gibertii (giberti passion fruit), in two types of grafting, hypocotyledonary and conventional, by cleft grafting method and one additional treatment, no grafted. The evaluated variables were: fruits length, diameter, fresh mass and classification from November 2006 to April 2007, the mass and the thickness of the peel of fruits, juice yield, total soluble solids (TSS) and titratable acidity of fruits (TA) and total soluble solid/titratable acidity relation (TSS/TA) in December 2006. The fruits diameter and mass obtained of rootstock plants on $P$. gibertii were inferior in no grafted plants and in plants of rootstock on $P$. alata. The bigger fruits lengths were obtained in no grafted plants. The different rootstocks did not promote difference in the TSS, TA and ratio. The grafting method did not affect the fruits length, diameter and mass, the mass and thickness of the peel, the juice yield and the TSS.
\end{abstract}

Index terms: yellow passion fruit, Passifloraceae, fruit quality.

\footnotetext{
${ }^{1}$ (Trabalho 227-10 ). Recebido em: 25-10-2010. Aceito para publicação em :19-05-2011. Parte da tese de doutorado do primeiro autor apresentado à FEIS/UNESP.

${ }_{2}^{2}$ Pesquisador da Polo da Alta Paulista/APTA, Caixa Postal 191, 17.800-000, Adamantina (SP), fone: (18) 3521-4266, e-mail: jccavichioli@apta.sp.gov.br.

${ }^{3}$ Professor Titular do Depto. de Fitotecnia, Tecnologia de Alimentos e Sócio-Economia da FEIS-UNESP, Ilha Solteira, e-mail: lcorrea@agr.feis.unesp.br

${ }^{4}$ Professor Adjunto do Depto. de Fitotecnia, Tecnologia de Alimentos e Sócio-Economia da FEIS-UNESP, Ilha Solteira, e-mail: boliani@agr.feis.unesp.br

${ }^{5}$ Professor do Depto. de Fitotecnia, Tecnologia de Alimentos e Sócio-Economia da FEIS-UNESP, Ilha Solteira, e-mail: santospc@agr.feis.unesp.br
} 


\section{INTRODUÇÃO}

O Passiflora edulis (maracujá-amarelo) é a principal espécie da família Passifloraceae cultivada no Brasil, devido às características físico-químicas de suas frutas, alta produtividade e grande aceitação do suco no mercado nacional (LIMA, 2002). Destinase tanto para industrialização quanto para consumo in natura.

O maracujá-amarelo representa 97\% da área plantada e do volume comercializado em todo o País com $60 \%$ da produção destinada ao consumo in natura e o restante destinado às indústrias de processamento, sendo o suco o principal produto (FERRAZ; LOT, 2006).

A aparência é o critério mais utilizado pelos consumidores para avaliar a qualidade dos frutos (ABREU et al., 2009). Uma fruta de qualidade é aquela que atende às expectativas dos diferentes segmentos consumidores, nas suas características internas e externas. As internas estão relacionadas ao sabor (sólidos solúveis totais e acidez) e conteúdo de suco (rendimento) (BALBINO, 2005). As características externas dos frutos devem atender a certos padrões para que atinjam a qualidade desejada na comercialização (NASCIMENTO et al., 1999).

O uso da enxertia no maracujazeiro é uma técnica descrita por diversos autores (CHAVES et al., 2004; SILVA et al., 2005; CAVICHIOLI et al., 2009), como forma de resolver problemas com algumas doenças de solo na cultura, como Fusarium solani e Phytophthora spp. (JUNQUEIRA et al., 2006). As técnicas da enxertia hipocotiledonar por garfagem tipo fenda cheia (CAVICHIOLI et al., 2009) e convencional por garfagem tipo fenda cheia (CORREA et al., 2010) mostraram-se viáveis para formação de mudas de maracujazeiro-amarelo, visando ao controle da morte prematura de plantas.

Alguns porta-enxertos são recomendados por serem resistentes ou tolerantes à morte prematura de plantas, como o $P$. gibertii e o $P$. alata (SÃO JOSÉ et al., 2000; RONCATTO et al., 2004; CAVICHIOLI et al., 2009). Apesar de Nogueira Filho et al. (2010) não terem observado diferenças entre as massas médias de frutos obtidos de plantas de maracujazeiro enxertadas com aquelas produzidas em plantas pé-franco, Junqueira et al. (2006) verificaram frutos com maior massa em plantas enxertadas. Estes autores também observaram que o rendimento de suco em frutos de plantas enxertadas é maior que aqueles obtidos de plantas por sementes, apesar de não apresentarem diferenças no teor de SST.

São escassas as informações sobre o efeito de porta-enxertos sobre as características físicas e químicas em frutos de maracujazeiro. Assim, o objetivo deste trabalho foi avaliar o efeito do portaenxerto e do tipo de enxertia sobre a qualidade dos frutos de maracujazeiro-amarelo.

\section{MATERIAL E MÉTODOS}

$\mathrm{O}$ experimento foi instalado no município de Adamantina-SP, na região da Nova Alta Paulista e conduzido em uma propriedade localizada a 397 $\mathrm{m}$ de altitude, $21^{\circ} 42^{\prime} 19^{\prime}$ 'S de latitude e $51^{\circ} 09^{\prime} 09^{\prime}$ 'W de longitude, no período de abril de 2006 a junho de 2007, em área sem histórico de morte prematura de plantas, utilizando-se de plantas enxertadas. O solo da área experimental, de acordo com a classificação da Embrapa (2006), é Argissolo Vermelho-Amarelo, eutrófico, A moderado, textura arenosa/média e topografia ondulada.

O clima da região, segundo a classificação de Köeppen, é do tipo Cwa, ou seja, tropical úmido com estação chuvosa no verão e estação seca no inverno. A precipitação média anual é de $1.300 \mathrm{~mm}$. A temperatura média anual está em torno de $22-23^{\circ} \mathrm{C}$.

Adotou-se o delineamento em blocos ao acaso, em esquema fatorial $3 \times 2+1$ tratamento adicional, com quatro repetições e cinco plantas/parcela. Os porta-enxertos avaliados foram: Passiflora edulis Sims, Passiflora alata Curtis e Passiflora gibertii N.E. Br., em dois sistemas de enxertia (hipocotiledonar e convencional por garfagem tipo fenda cheia) e um tratamento-testemunha (sem enxertia).

Para a produção de mudas utilizadas como porta-enxertos, as sementes de $P$. gibertii (maracujáde-veado) e $P$. alata (maracujá-doce) foram obtidas junto ao Departamento de Produção Vegetal da Faculdade de Ciências Agrárias e Veterinárias de Jaboticabal, FCAV, da Universidade Estadual Paulista, UNESP, e as sementes de $P$. edulis (maracujáamarelo), variedade Sul Brasil, foram coletadas em lavoura comercial no município de Adamantina, assim como aquelas utilizadas para produção dos garfos para a enxertia. Os materiais foram semeados no dia 19 de dezembro de 2005, utilizando-se de tubetes com $19 \mathrm{~cm}$ de comprimento por $5,5 \mathrm{~cm}$ de diâmetro contendo substrato comercial Bioplant ${ }^{\circledR}$, e a germinação ocorreu no período de $1^{\circ}$ a 9 de janeiro de 2006.

Utilizaram-se dois métodos de enxertia, a hipocotiledonar por garfagem tipo fenda cheia, realizada 25 dias após a emergência das plantas, e a convencional por garfagem tipo fenda cheia, realizada 60 dias após a emergência das plantas. Depois de enxertadas, as mudas foram tutoradas por uma estaca 
de madeira e mantidas em uma estufa agrícola com tela antiafídeo, colocando-se uma cobertura com tela de sombreamento. O sistema de irrigação adotado foi microaspersão.

O processo de condução foi espaldeira com dois fios de arame liso, fixo em mourões de 2,0 m de altura, espaçados de 5 metros. O espaçamento da cultura foi de 5,0 metros entre plantas por 3,2 metros entre ruas. Cada parcela foi constituída de cinco plantas, sendo consideradas úteis as três plantas centrais. A área total da parcela foi de $80 \mathrm{~m}^{2}$, e a área útil, de $48 \mathrm{~m}^{2}$.

O plantio das mudas foi realizado no dia 13 de abril de 2006, utilizando-se do sistema de plantio direto, controlando-se as ervas daninhas nas linhas com uso de herbicidas e nas entrelinhas, com uso de roçadeira. Antes do plantio, foi realizada uma análise de solo para verificar a necessidade de calagem e adubação. A correção da acidez do solo foi feita com base na recomendação de Piza Junior et al. (1996), seguindo o resultado da análise de solo (Tabela 1), aplicando-se 2 t/ha de calcário dolomítico (PRNT $76 \%, 28 \% \mathrm{CaO}, 16 \% \mathrm{MgO})$, parte em área total $(1,87 \mathrm{t} / \mathrm{ha})$ e parte na cova $(0,13 \mathrm{t} / \mathrm{ha})$. Foram abertas covas de 40 × $40 \times 40 \mathrm{~cm}$ e preenchidas com 40 litros de adubo orgânico, sendo 20 litros de organofértil $\left(1,25 \% \mathrm{~N}, 3,63 \% \mathrm{P}_{2} \mathrm{O}_{5}, 6,07 \% \mathrm{~K}_{2} \mathrm{O}\right)$ e 20 litros de composto de lixo $\left(1,3 \% \mathrm{~N}, 1,3 \% \mathrm{P}_{2} \mathrm{O}_{5}, 0,25 \% \mathrm{~K}_{2} \mathrm{O}\right)$, $600 \mathrm{~g}$ de superfosfato simples $\left(20 \% \mathrm{P}_{2} \mathrm{O}_{5}\right), 400 \mathrm{~g}$ de Yoorin $^{\circledR}\left(17,5 \% \mathrm{P}_{2} \mathrm{O}_{5}, 18 \% \mathrm{Ca}, 7 \% \mathrm{Mg}\right), 200 \mathrm{~g}$ de calcário dolomítico, $50 \mathrm{~g}$ de FTE $(9 \% \mathrm{Zn}, 1,8 \% \mathrm{~B}$, $0,8 \% \mathrm{Cu}, 2 \% \mathrm{Mn}, 3,5 \% \mathrm{Fe}, 0,1 \% \mathrm{Mo}$ ) e $300 \mathrm{~g}$ de condicionador de solo Ribumin ${ }^{\circledR}$.

As plantas foram conduzidas com um único ramo vegetativo (ramo primário) até atingir o segundo fio de arame, sendo que as brotações laterais foram eliminadas. Ao atingir o segundo fio, o ramo foi cortado no ápice, deixando crescer um ramo para cada lado da espaldeira (ramo secundário), o mesmo acontecendo com o $1^{\circ}$ fio de arame. Assim, ficaram dois ramos secundários para cada fio de arame, e os ramos que saíram desses foram chamados de ramos terciários e não foram desbrotados.

As pulverizações foram realizadas sempre no período da manhã para não afetar os insetos polinizadores. Para as lagartas, percevejos e besouros, foram utilizados produtos organofosforados. Para o controle de doenças fúngicas, foram efetuados tratamentos preventivos, utilizando-se da mistura de oxicloreto de cobre e mancozeb. Foi necessária uma pulverização curativa para antracnose, utilizando-se de um fungicida sistêmico do grupo dos triazóis.

Durante o período da experimentação, a eliminação das ervas daninhas foi realizada por capina manual na linha, e as entrelinhas foram mantidas vegetadas com gramíneas, sendo roçadas sempre que necessário como forma auxiliar de controle da virose. A polinização artificial foi realizada entre 14 e 17 horas, sempre que havia flores abertas.

As adubações de formação e produção foram realizadas com base no resultado da análise de solo (Tabela 1), obedecendo à recomendação de Piza Júnior et al. (1996), que correspondeu na fase de formação a $30 \mathrm{~g}$ de nitrato de amônio, aos 30 dias, 45 $\mathrm{g}$ de nitrato de amônio aos 60 dias, $100 \mathrm{~g}$ da fórmula 20-05-20 aos 90 dias e $150 \mathrm{~g}$ da fórmula 20-05-20 aos 120 dias após o plantio. Na adubação de produção, utilizaram-se $100 \mathrm{~kg} / \mathrm{ha}$ de $\mathrm{N}, 100 \mathrm{~kg} / \mathrm{ha}$ de $\mathrm{P}_{2} \mathrm{O}_{5}$ e $200 \mathrm{~kg} / \mathrm{ha}$ de $\mathrm{K}_{2} \mathrm{O}$, parcelado em 8 vezes no período de outubro de 2006 a maio de 2007.

Foram avaliadas as seguintes variáveis físicoquímicas:

a) Comprimento e diâmetro médio dos frutos: para a determinação destes parâmetros, coletou-se mensalmente, no período de novembro de 2006 a abril de 2007, uma amostra de 10 frutos/parcela, medindo-os com auxílio de um paquímetro de precisão $0,1 \mathrm{~mm}$.

b) Massa fresca média dos frutos: foi obtida dividindo-se a produção de cada colheita pelo número de frutos sadios. Efetuaram-se avaliações semanais para esta variável, no período de novembro de 2006 a abril de 2007.

c) Classificação dos frutos: foi realizada de acordo com as normas de classificação do Programa Brasileiro de Melhoria dos Padrões Comerciais e de Embalagens do maracujá-azedo (CEAGESP, 2001). Suas classes são determinadas pelo diâmetro equatorial do fruto, usando uma escala numérica de 1 a 5 , que correspondem a: classe 1, frutos com diâmetro igual ou menor que $55 \mathrm{~mm}$; classe 2 , frutos com diâmetro igual ou maior que 55 até $65 \mathrm{~mm}$; classe 3 , frutos com diâmetro igual ou maior que 65 até 75 $\mathrm{mm}$; classe 4 , frutos com diâmetro igual ou maior que 75 até $85 \mathrm{~mm}$, e classe 5, frutos com diâmetro maior que $85 \mathrm{~mm}$.

d) Massa média das cascas: obtida pela pesagem das cascas, após a retirada da polpa dos frutos.

e) Espessura da casca: após o corte e retirada da polpa, mediu-se a espessura da casca, com o auxílio de um paquímetro de precisão $0,1 \mathrm{~mm}$.

f) Rendimento de suco: após a pesagem dos frutos, foi retirada a polpa com uma colher e separada das sementes, determinando-se assim a massa e a porcentagem da mesma.

g) Determinação de sólidos solúveis totais (SST) e da acidez total titulável (ATT): foram realizadas no laboratório da UNESP - Câmpus de Ilha 
Solteira, no dia 18 de dezembro de 2006. O teor de SST foi obtido pela leitura direta em um refratômetro manual, com precisão de $0,20^{\circ} \mathrm{Brix}$, e a ATT foi determinada por titulação com uma solução de $0,1 \mathrm{~N}$ de $\mathrm{NaOH}$, expressa em porcentagem de ácido cítrico.

h) Ratio: foi obtido pela divisão direta do SST e da ATT.

\section{RESULTADOS E DISCUSSÃO}

O comprimento médio dos frutos variou de $9,92 \mathrm{~cm}$ no tratamento com $P$. gibertii a 10,91 $\mathrm{cm}$ em plantas pé-franco (Tabela 2), superiores aos obtidos por Nascimento et al. (1999), que variaram de 7,13 a $7,91 \mathrm{~cm}$, e dentro da faixa encontrada por Vianna-Silva et al. (2008), com $9,17 \mathrm{~mm}$ a 10,04 $\mathrm{mm}$. Os maiores frutos foram obtidos em plantas pé-franco, diferindo dos três tratamentos enxertados $(\mathrm{P}<0,01)$. Os frutos obtidos de porta-enxerto com $P$. gibertii apresentaram médias menores que os de pé-franco, diferindo do resultado encontrado por Oliveira et al. (1984), que não observaram diferenças entre os mesmos. Comparando-se os três porta-enxertos, verificou-se que frutos obtidos sobre $P$. alata foram maiores que de $P$. gibertii e $P$. edulis.

Os frutos com maiores diâmetros também foram obtidos em plantas pé-franco, com $8,24 \mathrm{~cm}$, não diferindo daqueles obtidos sobre o porta-enxerto P. alata, com $8,07 \mathrm{~cm}$ (Tabela 2), próximos aos valores encontrados por Vianna-Silva et al. (2008), com 7,80 cm, e superiores aos encontrados por Nascimento et al. (1999), que variaram de 6,56 a 7,32 $\mathrm{cm}$. Comparando os diâmetros dos frutos dos três porta-enxertos, verifica-se que não houve diferenças entre P. alata e P. edulis, que diferiram de P. gibertii. As diferenças observadas entre os porta-enxertos podem ter sido em função do vigor das plantas, uma vez que se trata de materiais de diferentes espécies, e como foi verificado por Nogueira Filho et al. (2010), plantas enxertadas em $P$. gibertii apresentaram menor vigor no campo, o que deve ter influenciado no comprimento e diâmetro médio dos frutos.

As maiores massas frescas de frutos foram obtidas sobre $P$. alata, com 223,04 g de média, que não diferiram das de $P$. edulis, com 218,44 g, mas foram superiores às de $P$. gibertii, com 199,68 g (Tabela 2), superando as encontradas por Junqueira et al. (2003), que variaram de 112,2 a $142,7 \mathrm{~g}$ e as de Cavichioli et al. (2008), na faixa de 144,24 a 149,83 g. As plantas pé-franco apresentaram massa média de $218,00 \mathrm{~g}$, diferindo apenas das de $P$. gibertii. Nogueira Filho et al. (2010) não verificaram diferenças nas massas de frutos entre estes porta-enxertos.

O comprimento e o diâmetro são parâmetros físicos de grande utilidade para frutos destinados ao mercado in natura que prefere frutos grandes e ovais. O critério para a classificação de frutos em maracujazeiro baseia-se no diâmetro do fruto (CEAGESP, 2001). Assim, de acordo com as normas de classificação, $87,7 \%$ dos frutos de maracujá colhidos de plantas pé-franco foram classificados como 4 ou 5 , ou seja, apresentaram diâmetro equatorial igual ou maior que $75 \mathrm{~mm}$, enquanto em frutos obtidos em $P$. alata, foi de $80,4 \%$, não diferindo de $P$. edulis, com $76,3 \%$, mas superior a $P$. gibertii, com $64,0 \%$ (Tabela 2). A enxertia hipocotiledonar proporcionou frutos de melhor classificação que na enxertia convencional. O tipo de enxertia não influenciou nas médias de comprimento, diâmetro e massa dos frutos.

As maiores massas de casca também foram observadas em plantas enxertadas sobre $P$. alata, que não diferiram de $P$. edulis, mas foram superiores a $P$. gibertii (Tabela 3 ).

Não houve diferenças entre os três portaenxertos para a espessura média de casca (Tabela 3 ). Verificou-se a maior espessura de casca em plantas pé-franco, com $9,72 \mathrm{~cm}$, que diferiu de $P$. alata e $P$. gibertii, com $8,30 \mathrm{~cm}$ e $8,08 \mathrm{~cm}$, respectivamente. Esses valores são superiores aos encontrados por Nascimento et al. (1999), que foram de 0,50 a 0,64 $\mathrm{cm}$, e por Fortaleza et al. (2005), que variaram entre 0,51 e $0,54 \mathrm{~cm}$. Segundo Oliveira et al. (1988), a maior espessura de casca relaciona-se com menor rendimento em suco, característica importante tanto para o mercado de frutos ao natural como para a indústria. De acordo com Bruckner et al. (2002), frutos destinados para a indústria precisam ter casca fina, possuir cavidade interna totalmente preenchida, conferindo alto rendimento de suco.

O maior rendimento de suco ocorreu em frutos obtidos do tratamento $P$. gibertii, com $34,5 \%$, que não diferiu de $P$. edulis, com 33,27\%, mas foi superior a P. alata, com 29,37\%. Esses valores estão próximos daqueles encontrados por Borges et al. (2003), variando de 32,8 a 34,3\%, e Cavichioli et al. (2008), na faixa de 29,25 a $34,94 \%$. Não houve diferenças entre as plantas pé-franco e os três porta-enxertos testados para esta variável.

Não houve correlação entre a massa fresca e a espessura da casca em frutos de maracujá (Tabela 4). Isto se explica porque não foram observadas diferenças entre os três porta-enxertos estudados para espessura de casca (Tabela 3). Assim, as diferenças verificadas para a massa média devem-se a outros fatores, como vigor do porta-enxerto e compatibilidade entre porta-enxerto/enxerto. Também não se observaram correlações significativas entre a massa fresca de frutos e espessura de casca com rendimentos 
de suco (Tabela 5).

De acordo com os resultados, verificou-se que o tipo de enxertia não interferiu na massa média dos frutos, na massa média da casca, na espessura da casca e no rendimento do suco.

Pela análise química dos frutos, verificou-se que não houve diferenças entre os tratamentos para sólidos solúveis totais e acidez total titulável (Tabela 5). O teor de sólidos solúveis totais é um parâmetro que tem sido utilizado como indicador da qualidade dos frutos destinados à industrialização, havendo preferência por frutos com teores de sólidos solúveis superiores a $13^{\circ}$ Brix (BRUCKNER et al., 2002). O teor de sólidos solúveis totais variou de 12,23 a 13,41, inferior aos encontrados por Borges et al. (2003), que variaram de 14,8 a $15,1 \%$, mas dentro da faixa aceitável para a indústria. A acidez titulável total variou de 3,9 em P. alata a 4,4 em P. giberti. Altos teores de ácidos no suco revelam uma característica importante no que diz respeito ao processamento, pois é interessante que os frutos possuam elevada acidez, visto que isso diminuiria a adição de acidificantes no suco (NASCIMENTO, 1996). Oliveira et al. (1994) e Nascimento (1996) consideram que, para a agroindústria, os frutos precisam apresentar elevado rendimento de suco, acidez total titulável e teor de sólidos solúveis totais elevados. No entanto, para mercado in natura, são preferidos frutos mais doces e menos ácidos.

Os frutos colhidos em plantas com enxertia hipocotiledonar apresentaram maior acidez total titulável e maior ratio que aqueles produzidos em enxertia convencional (Tabela 5). A razão sólidos solúveis totais e acidez total titulável (ratio) varia de 2,8 a 3,5, próximos daqueles encontrados por Borges et al. (2003), que variaram de 3,4 a 3,7.

TABELA 1 - Análise química do solo da área experimental. Adamantina-SP, 2006.

\begin{tabular}{|c|c|c|c|c|c|c|c|c|c|}
\hline $\begin{array}{r}\mathrm{pH} \\
\mathrm{CaCl}_{2}\end{array}$ & $\begin{array}{l}\text { M.O. } \\
\text { g/dm }\end{array}$ & $\begin{array}{c}\mathrm{P} \\
\mathrm{ng} / \mathrm{dm}^{3}\end{array}$ & $\mathrm{~K}$ & $\mathrm{Ca}$ & MG & $\begin{array}{r}\mathrm{Al} \mathrm{H}+\mathrm{Al} \\
\mathrm{mmol}_{\mathrm{c}} / \mathrm{dm}\end{array}$ & SB & СТC & $\begin{array}{l}\mathrm{V} \\
\% \\
\end{array}$ \\
\hline 4,5 & 7 & 8 & 2,6 & 6 & 3 & 20 & 11,6 & 31,6 & 37 \\
\hline
\end{tabular}

TABELA 2 - Médias de comprimento, diâmetro, massa e classificação de frutos de maracujazeiro-amarelo enxertados e pé-franco, no período de novembro de 2006 a abril de 2007. Adamantina-SP.

\begin{tabular}{|c|c|c|c|c|}
\hline Tratamentos & $\begin{array}{l}\text { Comprimento frutos } \\
(\mathrm{cm})\end{array}$ & $\begin{array}{l}\text { Diâmetro frutos } \\
(\mathrm{cm})\end{array}$ & Massa frutos $(\mathrm{g})$ & $\begin{array}{c}\text { Classificação (\%) } \\
\text { Classes } 4 \text { e } 5\end{array}$ \\
\hline \multicolumn{5}{|l|}{ Porta-Enxerto (P.E.) } \\
\hline P. alata & $10,41 \mathrm{a}$ & $8,07 \mathrm{a}$ & $223,04 \mathrm{a}$ & $80,4 \mathrm{a}$ \\
\hline P. gibertii & $9,92 \mathrm{~b}$ & $7,72 \mathrm{~b}$ & $199,68 \mathrm{~b}$ & $64,0 \mathrm{~b}$ \\
\hline P. edulis & $10,10 \mathrm{~b}$ & $7,95 \mathrm{a}$ & $218,44 \mathrm{a}$ & $76,3 \mathrm{ab}$ \\
\hline Teste F & $10,73 * *$ & $8,24 * *$ & $15,98 * *$ & $4,57 *$ \\
\hline DMS & 0,28 & 0,23 & 11,37 & 14,67 \\
\hline \multicolumn{5}{|l|}{ Enxertia (E) } \\
\hline Hipocotildedonar & 10,23 & 7,98 & 217,08 & $78,5 \mathrm{a}$ \\
\hline Convencional & 10,06 & 7,84 & 210,36 & $68,5 \mathrm{~b}$ \\
\hline Teste F & $3,83 \mathrm{~ns}$ & $3,72 \mathrm{~ns}$ & $3,54 \mathrm{~ns}$ & $4,72 *$ \\
\hline DMS & 0,19 & 0,16 & 7,62 & 9,83 \\
\hline Teste F (P.E x E.) & $0,75 \mathrm{~ns}$ & $1,05 \mathrm{~ns}$ & $1,33 \mathrm{~ns}$ & $0,73 \mathrm{~ns}$ \\
\hline $\mathrm{CV}(\%)$ & 2,13 & 2,21 & 4,10 & 15,37 \\
\hline Pé-franco & 10,91 & 8,24 & 218,00 & 87,7 \\
\hline Pé-franco x enxertado & $10,91 \times 10,14 * *$ & $8,24 \times 7,91 * *$ & $218,00 \times 213,72 \mathrm{~ns}$ & $87,7 \times 73,57 *$ \\
\hline Pé-franco x P. alata & $* *$ & $\mathrm{~ns}$ & ns & ns \\
\hline Pé-franco x $P$. gibertii & $* *$ & $* *$ & $* *$ & $* *$ \\
\hline Pé-franco x P. edulis & $* *$ & $*$ & ns & ns \\
\hline
\end{tabular}

Médias seguidas de letras distintas na coluna diferem entre si, significativamente, ao nível de $5 \%$ de probabilidade, pelo teste de Tukey. ns - não significativo

* significativo ao nível de $5 \%$

** significativo ao nível de $1 \%$ 
TABELA 3 - Massa média de frutos e de casca, espessura média de casca e rendimento de suco de maracujá-amarelo enxertado e pé-franco, avaliados em dezembro de 2006. Adamantina, SP.

\begin{tabular}{|c|c|c|c|c|}
\hline Tratamentos & $\begin{array}{l}\text { Massa de frutos } \\
(\mathrm{g})\end{array}$ & $\begin{array}{l}\text { Massa de casca } \\
(\mathrm{g})\end{array}$ & $\begin{array}{c}\text { Espessura de casca } \\
(\mathrm{mm})\end{array}$ & $\begin{array}{c}\text { Rendimento de suco } \\
(\%)\end{array}$ \\
\hline \multicolumn{5}{|l|}{ Porta-Enxerto (P.E.) } \\
\hline P. alata & $235,28 \mathrm{a}$ & $128,30 \mathrm{a}$ & 8,30 & $29,37 \mathrm{~b}$ \\
\hline P. gibertii & $183,87 \mathrm{~b}$ & $84,60 \mathrm{~b}$ & 8,08 & $34,50 \mathrm{a}$ \\
\hline P. edulis & $209,32 \mathrm{ab}$ & $101,93 \mathrm{ab}$ & 9,05 & $33,27 \mathrm{ab}$ \\
\hline Teste F & $4,42 *$ & $8,83 * *$ & $1,73 \mathrm{~ns}$ & $4,01 *$ \\
\hline DMS & 44,94 & 27,20 & 1,42 & 4,91 \\
\hline \multicolumn{5}{|l|}{ Enxertia (E) } \\
\hline Hipocotildedonar & 212,62 & 105,71 & 8,36 & 33,17 \\
\hline Convencional & 206,36 & 104,17 & 8,59 & 31,59 \\
\hline Teste F & $0,20 \mathrm{~ns}$ & $0,03 \mathrm{~ns}$ & $0,26 \mathrm{~ns}$ & $1,06 \mathrm{~ns}$ \\
\hline DMS & 30,11 & 18,22 & 0,95 & 3,29 \\
\hline Teste F (P.E x E.) & $0,27 \mathrm{~ns}$ & $0,51 \mathrm{~ns}$ & $0,24 \mathrm{~ns}$ & $0,61 \mathrm{~ns}$ \\
\hline CV $(\%)$ & 16,52 & 19,96 & 12,89 & 11,67 \\
\hline Pé-franco & 214,74 & 113,94 & 9,72 & 32,35 \\
\hline \multicolumn{3}{|c|}{ Pé-franco x enxertado 214,74 x 209,49 ns 113,94 x 104,94 ns } & $9,72 \times 8,47 *$ & $32,35 \times 32,38 \mathrm{~ns}$ \\
\hline Pé-franco x P. alata & ns & ns & $*$ & $\mathrm{~ns}$ \\
\hline Pé-franco x $P$. gibertii & ns & $*$ & $*$ & ns \\
\hline Pé-franco x P. edulis & ns & ns & ns & ns \\
\hline
\end{tabular}

Médias seguidas de letras distintas na coluna diferem entre si, significativamente, ao nível de 5\% de probabilidade, pelo teste de Tukey. ns - não significativo

* significativo ao nível de $5 \%$

** significativo ao nível de $1 \%$

TABELA 4 - Coeficientes de correlação de Pearson entre Massa média de frutos (X) e Rendimento (Y) com Espessura de casca $(Z)$ de maracujá-amarelo enxertado em três porta-enxertos. AdamantinaSP, 2006/2007.

\begin{tabular}{lccc}
\hline \multicolumn{4}{c}{ Coeficientes de correlação } \\
\hline Porta-enxertos & $\begin{array}{c}\text { Massa média de frutos (X) } \\
\text { e Espessura de casca }(\mathrm{Z})\end{array}$ & $\begin{array}{c}\text { Massa média de frutos } \\
(\mathrm{X}) \text { e Rendimento de } \\
\text { suco }(\mathrm{Y})\end{array}$ & $\begin{array}{c}\text { Rendimento de suco (Y) e } \\
\text { Espessura de casca (Z) }\end{array}$ \\
\hline P. alata & $0,301 \mathrm{~ns}$ & $-0,053 \mathrm{~ns}$ & $-0,505 \mathrm{~ns}$ \\
P. gibertii & $0,117 \mathrm{~ns}$ & $-0,257 \mathrm{~ns}$ & $-0,567 \mathrm{~ns}$ \\
P. edulis & $-0,304 \mathrm{~ns}$ & $-0,139 \mathrm{~ns}$ & $-0,531 \mathrm{~ns}$ \\
\hline
\end{tabular}

ns - não significativo a $5 \%$, pelo teste t.

TABELA 5 - Sólidos Solúveis Totais (SST), Acidez Total Titulável (ATT), ratio (SST/ATT) de maracujáamarelo enxertado e pé-franco, avaliado em dezembro de 2006. Adamantina-SP. 
Tratamentos

Sólidos Solúveis Totais

(SST)
Acidez Titulável Total

(ATT)
Ratio

$(\mathrm{SST} / \mathrm{ATT})$

\begin{tabular}{lccc}
\hline Porta-Enxerto (P.E.) & \multicolumn{3}{c}{} \\
\hline P. alata & 12,82 & 3,9 & 3,4 \\
P. gibertii & 12,79 & 4,4 & 3,0 \\
P. edulis & 13,30 & 3,9 & 3,4 \\
\hline Teste F & $0,53 \mathrm{~ns}$ & $2,43 \mathrm{~ns}$ & $4,05 *$ \\
DMS & 1,44 & 0,54 & 0,42 \\
\hline Enxertia (E) & & & $3,0 \mathrm{~b}$ \\
\hline Hipocotildedonar & 12,67 & $4,3 \mathrm{a}$ & $3,5 \mathrm{a}$ \\
Convencional & 13,27 & $3,9 \mathrm{~b}$ & $14,10 * *$ \\
\hline Teste F & $1,77 \mathrm{~ns}$ & $5,94 *$ & 0,28 \\
DMS & 0,96 & 0,36 & $4,55 *$ \\
\hline Teste F (P.E x E.) & $0,59 \mathrm{~ns}$ & $2,06 \mathrm{~ns}$ & 9,98 \\
CV $(\%)$ & 8,53 & 10,26 & 3,5 \\
\hline Pé-franco & 12,93 & 3,9 & $3,5 \times 3,2 *$ \\
\hline Pé-franco x enxertado & $12,93 \times 12,97 \mathrm{~ns}$ & $3,9 \mathrm{x} 4,07 \mathrm{~ns}$ & $*$ \\
\hline Pé-franco x P. alata & $\mathrm{ns}$ & $\mathrm{ns}$ & $\mathrm{ns}$ \\
Pé-franco x P. gibertii & $\mathrm{ns}$ & $\mathrm{ns}$ & $\mathrm{ns}$ \\
Pé-franco x P. edulis & $\mathrm{ns}$ & $\mathrm{ns}$ & \\
\hline
\end{tabular}

Médias seguidas de letras distintas na coluna diferem entre si significativamente, ao nível de 5\% de probabilidade, pelo teste de Tukey. ns - não significativo

* significativo ao nível de $5 \%$

** significativo ao nível de $1 \%$

TABELA 6 -Teste de Tukey para o desdobramento dos porta-enxertos (P.E.) dentro dos tipos de enxertia (E) para ratio (SST/ATT) de frutos de maracujazeiro-amarelo enxertado, avaliado em dezembro de 2006. Adamantina-SP.

\begin{tabular}{lcc}
\hline & \multicolumn{2}{c}{ Tipos de enxertia (E) } \\
\cline { 2 - 3 } Porta-enxertos (P.E.) & Hipocotiledonar & Convencional \\
\hline P. alata & $2,8 \mathrm{a}$ & $3,9 \mathrm{a}$ \\
P. gibertii & $2,9 \mathrm{a}$ & $3,1 \mathrm{~b}$ \\
P. edulis & $3,3 \mathrm{a}$ & $3,5 \mathrm{~b}$ \\
\hline
\end{tabular}

Médias seguidas de letras distintas, na coluna, diferem entre si, pelo teste de Tukey, a 5\% de probabilidade

\section{CONCLUSÕES}

1-Plantas enxertadas dão origem a frutos dentro dos padrões de comercialização, apesar de apresentarem comprimentos menores que as plantas pé-franco.

2-Plantas enxertadas em Passiflora gibertii apresentam frutos com diâmetro e massa fresca de frutos menores que plantas pé-franco e plantas enxertadas sobre $P$. alata.
3-O método de enxertia não interfere no diâmetro, no comprimento, na massa fresca média dos frutos, na massa média e na espessura da casca, no rendimento do suco e no teor de sólidos solúveis totais.

4-O uso de diferentes porta-enxertos não afeta o teor de sólidos solúveis totais e a acidez titulável total em frutos de maracujazeiro-amarelo. 


\section{REFERENCIAS}

ABREU, S. de P.M.; PEIXOTO, J.R.; JUNQUEIRA, N.T.V.; SOUSA, M.A. de F. Características físicoquímicas de cinco genótipos de maracujazeiro-azedo cultivados no Distrito Federal. Revista Brasileira de Fruticultura, Jaboticabal, v.31, n.2, p.487-491, 2009.

BALBINO, J.M. de S. Manejo na colheita e póscolheita do maracujá. In: COSTA, A. de F.S.; COSTA, A.N. (Eds.). Tecnologias para a produção de maracujá. Vitória: INCAPER, 2005. p. 153-179.

BORGES, A.L.; RODRIGUES, M.G.V.; LIMA, A.de A.; ALMEIDA, I.E.; CALDAS, R.C. Produtividade e qualidade de maracujá-amarelo irrigado, adubado com nitrogênio e potássio. Revista Brasileira de Fruticultura, Jaboticabal, v.25, n.2, p.259-262, 2003.

BRUCKNER, C.H.; MELETTI, L.M.M.; OTONI, W.C.; ZERBINI JÚNIOR, F.M. Maracujazeiro. In. BRUCKNER, C.H. (Ed.). Melhoramento de fruteiras tropicais. Viçosa: UFV, 2002. p.373-410.

CAVICHIOLI, J.C.; CORRÊA, L. de S.; BOLIANI, A.C.; OLIVEIRA, J.C. de. Uso de câmara úmida em enxertia hipocotiledonar de maracujazeiro-amarelo sobre três porta-enxertos. Revista Brasileira de Fruticultura, Jaboticabal, v.31, n.2, p.532-538, 2009.

CAVICHIOLI, J.C.; RUGGIERO, C.; VOLPE, C.A. Caracterização físico-química de frutos de maracujazeiro-amarelo submetidos à iluminação artificial, irrigação e ao sombreamento. Revista Brasileira de Fruticultura, Jaboticabal, v. 30, n.3, p.649-656, 2008.

CEAGESP - Companhia de Entrepostos e Armazéns Gerais de São Paulo. Classificação do maracujá (Passiflora edulis Sims). Programa Brasileiro para a Melhoria dos Padrões Comerciais e de Embalagens do Maracujá-Azedo. 2001. Disponível em: <www. ceagesp.com.br>.

CHAVES, R.C.; JUNQUEIRA, N.T.V.; MANICA, I.; PEIXOTO, J.R.; PEREIRA, A.V.; FIALHO, J.F. Enxertia de maracujazeiro-azedo em estacas herbáceas enraizadas de espécies de passifloras nativas. Revista Brasileira de Fruticultura, Jaboticabal, v.26, n.1, p.120-123, 2004.
CORRÊA, L.de S.; CAVICHIOLI, J.C.C.; OLIVEIRA, J.C. de; BOLIANI, A.C. Uso de câmara úmida em enxertia convencional de maracujazeiroamarelo sobre três porta-enxertos. Revista Brasileira de Fruticultura, Jaboticabal, v.32, n.2, p.591-598, 2010.

EMBRAPA. Centro Nacional de Pesquisa de Solo. Sistema brasileiro de classificação de solos. 2.ed. Rio de Janeiro, 2006. 306p.

FERRAZ, J.V.; LOT, L. Fruta para consumo in natu$r a$ tem boa perspectiva de renda. In: AGRIANUAL 2007: anuário da agricultura brasileira. Maracujá. São Paulo: FNP Consultoria e Comércio, 2006. p.387-388.

FORTALEZA, J.M.; PEIXOTO, J.R.; JUNQUEIRA, N.T.V.; OLIVEIRA, A.T. de; RANGEL, L.E.P. Características físicas e químicas em nove genótipos de maracujá-azedo cultivado sob três níveis de adubação potássica. Revista Brasileira de Fruticultura, Jaboticabal, v.27, n.1, p.124-127, 2005.

JUNQUEIRA, N.T.V.; ANJOS, J.R.N. dos; SILVA, A.P. de O.; CHAVES, R.da C.; GOMES, A.C. Reação às doenças e produtividade de onze cultivares de maracujá-azedo cultivadas sem agrotóxicos. Pesquisa Agropecuária Brasileira, Brasília, v.38, n. 8 , p. 1005-1010, 2003

JUNQUEIRA, N.T.V.; LAGE, D.A. da C.; BRAGA, M.F.; PEIXOTO, J.R.; BORGES, T.A.; ANDRADE, S.R.M. de. Reação a doenças e produtividade de um clone de maracujazeiro-azedo propagado por estaquia e enxertia em estacas herbáceas de Passiflora silvestre. Revista Brasileira de Fruticultura, Jaboticabal, v.28, n.1, p.97-100, 2006.

LIMA, A.de A. Maracujá produção: introdução. In: LIMA, A.de A. (Ed.). Maracujá produção: aspectos técnicos. Brasília: Embrapa. Informação Tecnológica, 2002. p.9.

NASCIMENTO, T.B. do. Qualidade do maracujáamarelo produzido em diferentes épocas no sul de Minas Gerais. 1996. 56 f. Dissertação (Mestrado em Fitotecnia) - Universidade Federal de Lavras, Lavras, 1996. 
NASCIMENTO, T.B. do; RAMOS, J.D.; MENEZES, J.B. Características físicas do maracujá-amarelo produzido em diferentes épocas. Pesquisa Agropecuária Brasileira, Brasília, v.34, n.12, p.2353-2358, 1999.

NOGUEIRA FILHO, G.C.; RONCATTO, G.; RUGGIERO, C.; OLIVEIRA, J.C. de; MALHEIROS, E.B. Desenvolvimento e produção das plantas de maracujazeiro-amarelo produzidas por enxertia hipocotiledonar sobre seis porta-enxertos. Revista Brasileira de Fruticultura, Jaboticabal, v.32, n.2, p.535-543, 2010.

OLIVEIRA, J.C. de; FERREIRA, F.R.; RUGGIERO, C.; NAKAMURA, L. Caracterização e avaliação de germoplasma de Passiflora edulis. In: CONGRESSO BRASILEIRO DE FRUTICULTURA, 9., 1987, Campinas. Anais... Campinas: SBF, 1988. v.2, p.591-596.

OLIVEIRA, J.C de.; NAKAMURA, K.; MAURO, A.O.; CENTURION, M.A.P.C. Aspectos gerais do melhoramento do maracujazeiro. In: SÃO JOSÉ, A.R. Maracujá: produção e mercado. Vitória da Conquista: DFZ/UESB, 1994. p.27-37.

OLIVEIRA, J.C. de; RUGGIERO, C.,; NAKAMURA, K..; BAPTISTA, M. Comportamento de Passiflora edulis enxertada sobre P. gibertii N.E. Brown. In: CONGRESSO BRASILEIRO DE FRUTICULTURA, 7., 1983, Florianópolis. Anais... Florianópolis: EMPASC/SBF, 1984. v.3, p.989-93.
PIZA JUNIOR, C. de T.; QUAGGIO, J.A.; MELETTI, L.M.M.; SILVA, J.R da; SÃO JOSÉ, A.R.; KAVATI, R. Maracujá. In: RAIJ, B. Van; CANTARELLA, H.; QUAGGIO, J.A.; FURLANI, A.M.C. Recomendações de adubação e calagem para o Estado de São Paulo. 2.ed. Campinas: Instituto Agronômico, 1996. 285p. (Boletim Técnico, 100).

RONCATTO, G.; OLIVEIRA, J.C.de R.C.; NOGUEIRA FILHO, G.C.; CENTURION, M.A.P.da C.; FERREIRA, F.R. Comportamento de maracujazeiros (Passiflora spp.) quanto à morte prematura. Revista Brasileira de Fruticultura, Jaboticabal, v.26, n.3, p.552-554, 2004.

SÃO JOSÉ, A.R.; SANTOS, A.; SILVA, A.C. da;BONFIM, M.P.; MORAIS, O.M.; ATAÍDE, E.M.; BARBOSA, N.M.L. Fusariose no semiárido. In: CONGRESSO BRASILEIRO DE FRUTICULTURA, 16., 2000, Fortaleza. Anais...p.470. Jaboticabal: Sociedade Brasileira de Fruticultura, 2000. CD-ROM

SILVA, F.M.; CORRÊA, L.de S.; BOLIANI, A.C.; SANTOS, P.C. dos. Enxertia de mesa de Passiflora edulis Sims f. flavicarpa Deg. sobre Passiflora alata Curtis, em ambiente de nebulização intermitente. Revista Brasileira de Fruticultura, Jaboticabal, v.27, n.1, p.98-101, 2005.

VIANNA-SILVA, T.; RESENDE, E.D. de; PEREIRA, S.M. de F.; VIANA, A.P.; ROSA, R.C.C.; CARLOS, L. de A.; VITORAZI, L. Influência dos estádios de maturação sobre as características físicas dos frutos de maracujá-amarelo. Bragantia, Campinas, v.67, n.2, p.521-525, 2008. 